\title{
O Marxismo e a Atual Crise Ecológica
}

\section{Marxism and the Current Ecological Crisis}

Matheus Hein Souza ${ }^{1}$

\section{Resumo}

O presente artigo tem por objetivo examinar as possibilidades de uma análise marxista da atual crise ecológica global. Para tal, o trabalho utilizar-se-á do referencial teórico desenvolvido por diferentes autores da corrente "ecossocialista" da tradição marxista, assim como o conjunto de obras produzidas pelo filósofo marxista húngaro István Mészaros. De tal maneira, a intenção é compreender as características próprias do regime sociometabólico do capital, relacionando-o com as condições que originam a situação ecológica que se presencia.

Palavras-chave: Metabolismo Social. Ecologia. Ecossocialismo.

\begin{abstract}
This article aims to examine the possibilities for a Marxist analysis of the current global ecological crisis. To this end, the work will use the theoretical framework developed by different authors of the "eco-socialist" current of the Marxist tradition, as well as the set of works produced by the Hungarian Marxist philosopher István Mészaros. In such a way, the intention is to understand the characteristics of the sociometabolic regime of capital, relating it with the conditions that originate the ecological situation that is witnessed.
\end{abstract}

Keywords: Social Metabolism. Ecology. Eco-socialism.

\section{Introdução}

É possível elencar um conjunto de elementos que apontam a necessidade e

\footnotetext{
${ }^{1}$ Mestrando do Programa de Pós-Graduação em Filosofia da Pontifícia Universidade Católica do Rio Grande do Sul (PUCRS). Bolsista CNPq. E-mail: matheushein@gmail.com
} 


\section{2 | Dossiê - Natureza e Sociedade no Antropoceno - Superando a Separação?}

urgência de se tratar das questões referentes à destruição da natureza: crise climática, escassez de alimentos, crises hídricas, aumento da poluição, pandemias. Um emaranhando de crises parece ter como ponto de partida a relação entre sociedade e natureza, relação esta que se demonstra cada vez mais insustentável. Como resultado disso, cresce o número de pesquisadores - de áreas múltiplas, que vão desde a biologia até a filosofia - que dedicam suas carreiras a compreender as razões de tal situação, assim como apontar possíveis saídas deste ciclo destrutivo. Uma constatação comum que diferentes pesquisadores parecem chegar é a de que a forma que se produz, distribui e consome na nossa sociedade está diretamente relacionada com a predação problemática dos recursos naturais. As soluções para isso variam, não havendo consenso sobre como proceder.

A crise ecológica, é claro, não se dá em um vácuo, separada do restante da sociedade. Entre constantes crises econômicas e de legitimidade política em vários países, é possível afirmar que o tempo atual é marcado pelo signo da crise. Tal situação evoca a memória de Marx, um dos - se não o maior - críticos do atual modelo societário. De todo modo, uma série de características foram atribuídas à Marx, seu pensamento e os herdeiros de seu legado teórico, muitas vezes o taxando como positivista e determinista, desenvolvimentista e produtivista. Em grande parte, é possível afirmar que a compreensão do marxismo como algo não apenas não relacionável com o pensamento ecológico, mas diametralmente hostil a tais noções, se deve pela experiência do socialismo soviético. John Bellamy Foster afirma que a URSS foi pioneira em medidas protetivas ao meio ambiente, mas

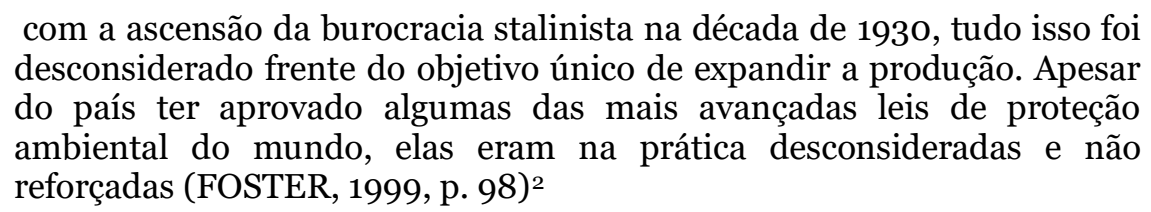

Todos os métodos que hoje podem ser apontados como nefastos e prejudiciais na civilização capitalista, também podem ser identificados na trajetória da União Soviética. Foster detalha, por exemplo, a cultura catastrófica da agricultura russa durante os anos de domínio soviético:

A agricultura soviética dependia muito de produtos químicos, muitas vezes contra a lei. No final dos anos 1970 e início dos anos 1980, a tonelagem de pesticidas usados na agricultura soviética aumentaram. Embora banido

\footnotetext{
${ }^{2}$ Todas as citações referentes a este livro foram traduzidas livremente da versão original em inglês 
dois anos antes do que nos Estados Unidos, o DDT foi aplicado em certas regiões com a permissão secreta dos ministérios de Agricultura e Florestamento (FOSTER, 1999, p. 99).

Os exemplos podem continuar em outras áreas, mas o que cabe constatar é que a busca por um aumento da produtividade na Rússia - dentro do contexto de Guerra Fria e enfrentamento com os Estados Unidos da América, maior potência econômica e militar naquele momento, é bom lembrar - impeliu os governantes a garantir o desenvolvimento das forças produtivas do país às custas da natureza compreendida nos limites do seu território, que se expandia por uma larga região do Leste Europeu. De todo modo, atribuir os descaminhos da URSS à Marx é uma conclusão demasiadamente apressada.

Do mesmo modo que é verdadeiro afirmar que as experiências do socialismo dito real desconsideram por completo a natureza, também é absolutamente verdadeiro afirmar que Marx levou em conta em toda a sua obra a natureza. Quando era jornalista da Gazeta Renana, Marx escreve sobre a condenação, por ele considerada absurda, de camponeses que "furtavam" galhos secos. O, então, jovem filósofo, afirma algo que é carregado de uma "sensibilidade ecológica": "Para aproriar-se de madeira verde é preciso separá-la com violência de sua ligação orgânica. Assim como isso representa um atentado evidente contra a árvore, representa um atentado evidente contra o proprietário da árvore" (MARX, 2017a [1842], p. 80). É claro, a partir de uma simples "sensibilidade ecológica" como essa não é razoável inferir que a obra de Marx carrega uma noção importante da natureza. De todo modo, considerações sobre o mundo natural são feitas constantemente na obra de Marx. Poucos anos depois de denunciar a injusta lei que penalizava aqueles que colhiam galhos, Marx afirma, nos seus Manuscritos Econômico-Filosóficos, que "como a natureza oferece os meios de vida, no sentido de que o trabalho não pode viver sem objetos nos quais se exerça, assim também oferece, por outro lado, os meios de vida no sentido mais estrito, isto é, o meio de subsistência física do trabalhador mesmo" (MARX, 2010 [1844], p. 81). Entretanto, ele aprofunda sua concepção, asserindo que "a vida física e mental do homem está interconectada com a natureza não tem outro sentido senão que a natureza está interconectada consigo mesma, pois o homem é uma parte da natureza” (MARX, 2010 [1844], p.82). Isto é, Marx leva em conta que sem natureza não há possibilidade de trabalho, assim como não há possibilidade de existência humana - logo, é possível inferir que seria temerário destruir aquilo que possibilita as 


\section{4 | Dossiê - Natureza e Sociedade no Antropoceno - Superando a Separação?}

condições de existência da humanidade. Ainda assim, Marx vai mais longe e afirma claramente que o homem, apesar de todo contexto industrial e desenvolvido, é ainda parte da natureza. Estas considerações não existem apenas no “jovem Marx”, mas é possível encontrar constatações como a de que a natureza, junto com o trabalho, é a origem da riqueza (MARX, 2012 [1875], p. 17) e chega até mesmo ao Capital, como será abordado posteriormente. Sendo assim, não é correto afirmar que do pensamento de Marx decorrem as mazelas da experiência soviética no que diz respeito aos desastres ecológicos daquela nação. De todo modo, também não é possível encontrar em Marx as respostas necessárias para as crises ecológicas do nosso tempo.

Assim sendo, pode-se asserir que o método marxiano é sim habilitado a dar respostas quanto a questão ambiental. A análise materialista e dialética da realidade não é, a priori, anti-ecológica, ou uma que leve necessariamente a resultados produtivistas e destrutivos. Por esta razão, o presente artigo utiliza a produção teórica de autores ecossocialistas, como o supracitado Foster, e também do marxista húngaro István Mészáros, de modo a se inserir na esteira de análises que visam compreender a atual condição ecológica que o mundo se encontra - e também encontrar as respostas para os desafios atuais.

\section{Os imperativos e a incontrolabilidade do capital}

O filósofo húngaro István Mészáros se debruça na sua obra na tentativa de revitalizar a crítica marxista ao sistema do capital. Nesse sentido, sua produção teórica vai no caminho de dissipar incompreensões e distorções que ocorrem no decorrer do século XX em relação ao método de Marx, assim como as conclusões alcançadas na sua aplicação. Um dos pontos cruciais para Mészáros é demonstrar que o “objeto da crítica de Marx não era o capitalismo, mas o capital” (MÉSZÁROS, 2002, p. 721, grifos do autor). Isto é, Marx - e Mészáros, enquanto continuador da crítica - não está interessado em criticar o modo de produção capitalista unicamente, mas interpretar o funcionamento do capital em si, nas suas variadas formações e nas distintas configurações históricas que lhe são possíveis. É nesse sentido que "o capital pode ser identificado em formações sociais anteriores, mas apenas sob a forma de capital-comercial ou capital-dinheiro" (MELO, 2018, p. 1819), sendo assim identificável em outras formações sociais que não a capitalista. Do 
mesmo modo, é possível identificar a permanência do capital em Estados póscapitalistas, como o de tipo soviético (MÉSZÁROS, 2002). A grande questão que Mészáros se coloca e visa analisar é o que são as características e imperativos próprios do capital, aquilo que dota o capital de uma natureza única e que permanece mesmo em configurações não capitalistas.

O filósofo define o sistema do capital como

um sistema orgânico de reprodução sociometabólica, dotado de lógica própria e de um conjunto objetivo de imperativos, que subordina a si (...) todas as áreas da atividade humana, desde os processos econômicos mais básicos até os domínios intelectuais e culturais mais mediados e sofisticados. (MÉSZAROS, 2004, p. 16)

Nesse sentido o regime sociometabólico do capital é

uma poderosa (...) estrutura totalizadora (...) que sujeita cegamente aos mesmos imperativos a questão da saúde e a do comércio, a educação e a agricultura, a arte e a indústria manufatureira, que implacavelmente sobrepõe a tudo seus próprios critérios de viabilidade, desde as menores unidades de seu "microcosmo" até as mais gigantescas empresas transnacionais, desde as mais íntimas relações pessoais aos mais complexos processos de tomada de decisão dos vastos monopólios industriais, sempre a favor dos fortes e contra os fracos. (MÉSZÁROS, 2002, p. 96)

Tal é o potencial totalizador do capital que faz até mesmo com que os trabalhadores, sujeitos antagônicos às necessidades do capital, internalizem "os imperativos do capital como seus próprios" (MÉSZÁROS, 2002. p. 628). Assim, o regime sociometabólico do capital é um modo de controle que se estende à totalidade da sociedade, carregando consigo os seus imperativos para todos os terrenos, sejam eles econômicos ou não. Enquanto estrutura totalizadora, o capital subordina aos seus imperativos a tudo e todos.

Estabelecido do que se trata o regime do capital, é preciso compreender suas condições de existência e imperativos, ou necessidades. Primeiro no tocante às condições, Mészáros afirma que

Em todas as formas concebíveis da relação-capital desenvolvida incluindo as formas pós-capitalistas - as condições necessárias são: (1) a separação e a alienação das condições objetivas do processo de trabalho do próprio trabalho; (2) a imposição de tais condições objetivadas e alienadas sobre os trabalhadores como um poder separado que exerce comando sobre o trabalho; (3) a personificação do capital como "valor egoísta" - com sua subjetividade usurpada e sua pseudopersonalidade que persegue sua própria autoexpansão, com uma vontade própria (sem a qual não poderia ser "capital-para-si" como controlador do sociometabolismo); (...); e (4) a equivalente personificação do trabalho 
(isto é, a personificação dos trabalhadores como "trabalho" destinado a entrar numa relação de dependência ou contratual/econômica ou politicamente regulada com o tipo historicamente prevalecente de capital). (MÉSZÁROS, 2002, p. 720-721, grifos do autor).

De acordo com Maria Cristina Soares Paniago, “esses pressupostos devem vigorar simultaneamente, pois, de outra forma, inviabilizariam o próprio sociometabolismo como hoje é constituído. Sua dinâmica expansiva que é a "real força motriz' do sistema” (PANIAGO, 2012, p. 32-33). A exposição das condições feita por Mészáros, assim como o comentário de Paniago, já indicam um fator de necessidade central para o capital: a expansão. Mészáros assere que "o sistema do capital é um modo de controle sociometabólico incontrolavelmente voltado para a expansão" (MÉSZÁROS, 2002, p. 131), isto é, “é por sua natureza mais íntima orientado para a expansão e impulsionado pela acumulação” (MÉSZÁROS, 2013, p. 103). Estas duas dimensões - expansão e acumulação - estão intimamente ligadas, fazem parte de um circuito vital para a garantia de existência e reprodução do capital. O capital necessita de um constante processo de acumulação para garantir sua viabilidade reprodutiva, isto é, o capital precisa constantemente apoderar-se do excedente produtivo para garantir suas possibilidades de reprodução. Em uma analogia que representa perfeitamente a relação entre capital e trabalho, Marx o compara com um vampiro que vive de sugar o trabalho (MARX, 2013 [1867], p. 307). O "sangue" extraído do trabalho pelo capital é o excedente que ele se apodera e necessita para existir.

De todo modo, para garantir as condições de acumulação, o capital também necessita de um irrefreável movimento de expansão. Esta expansão se dá geograficamente, como constatado no decorrer da história e, por exemplo, na expansão colonialista do século XVI. Marx e Engels apontam já no Manifesto do Partido Comunista a relação estreita entre a expansão colonial e o momento de nascimento do capitalismo europeu

A descoberta da América e a circunavegação da África abriram um novo campo de ação para a burguesia nascente. Os mercados da Índia e da China, a colonização da América, o comércio com as colônias, o aumento dos meios de troca e do volume das mercadorias em geral trouxeram uma prosperidade até então desconhecida para o comércio, a navegação e a indústria e, com isso, desenvolveram o elemento revolucionário dentro da sociedade feudal em desintegração. (ENGELS; MARX, 2008 [1848], p. 1112)

Osvaldo Coggiola liga o processo de colonização com o processo de 
acumulação primitiva do capital (2011) e Fábio Mascaro Querido aponta a “acumulação e espoliação 'primitivas' que, na periferia do sistema (...), são permanentes" (2013, p. 89). Antes destes, Enrique Dussel já associava a invasão das Américas com o processo fundante da modernidade burguesa (1994). De todo modo, em tempos de consolidada globalização, parece não haver mais recantos no mundo que não foram tomados pela lógica totalizadora do capital. Compreendendo isto, Mészáros faz a distinção entre "totalidade extensiva" e "totalidade intensiva" do capital. Ao fazê-lo, Mészáros pontua que "até onde dizia respeito à 'totalidade intensiva' dos vastos territórios já descobertos e anexados, o sistema do capital estava muito longe de alcançar os limites de sua expansão e acumulação produtiva" (MÉSZÁROS, 2002, p. 90). Isto é, a expansão do capital não se limita ao aspecto geográfico ou territorial, mas abrange os ritmos, padrões e intensidades de exploração e extração de mais-valia - e aqui seria justo acrescentar a exploração e extração da natureza, que será melhor abordado posteriormente. Para o filósofo húngaro, a importância da "totalidade intensiva" é tanta que "nesse sentido, o tamanho do 'mundo redondo' poderá muito bem ser dobrado, ou multiplicado por dez, dependendo de uma série de outras condições e circunstâncias - inclusive políticas" (MÉSZÁROS, 2002, p. 591).

Uma última pontuação em relação ao circuito de expansão-acumulação é de que a expansão tem no regime do capital funções para além da abertura de novos territórios para acumulação. A expansão nesse regime sociometabólico também desempenha o papel de deslocamento das contradições do capital. O metabolismo social do capital, como qualquer sistema, é repleto de contradições e algumas destas contradições emergem como consequências secundárias das suas dinâmicas. Outras, entretanto, são fruto de imperfeições estruturais, ou dito de outra maneira, são contradições inerentes ao sistema do capital. Ao se tratar destas contradições, "o capital deve procurar soluções para todos os problemas e contradições gerados em sua estrutura por meio de ajustes feitos estritamente nos efeitos e nas consequências" (MÉSZÁROS, 2002, p. 175, grifos do autor). Sua atuação se dá apenas nos efeitos e nas consequências, pois a causa para elas é o próprio regime do capital, dada as origens das contradições localizadas na própria estrutura. É neste referencial que a expansão possui papel vital, sendo "uma maneira absolutamente necessária de deslocar os problemas e contradições que emergem no sistema do capital, de acordo com o imperativo de evitar, como praga, as causas subjacentes" 
(MÉSZÁROS, 2002, p. 176, grifos do autor). Seja deslocando as contradições para outra parte do mundo ou para outros setores da economia, é o movimento expansivo do capital que garante o adiamento da eclosão de crises resultantes das lógicas contraditórias emergentes dos defeitos estruturais do capital.

\subsection{Um regime incontrolável}

Tendo em vista a configuração do regime do capital como um regime de permanente expansão e acumulação, se torna evidente que se trata de um regime que não pode conhecer limitações a esses processos. A sua dimensão totalizadora e expansão-acumulação irrefreáveis, tornam o capital incontrolável. Por um lado, está na sua própria raiz, nas condições necessárias supracitadas, a natureza alienante da qual o capital é gerador e gerado, alienação esta que recai sobre a relação do trabalhador com sua atividade produtiva. É imprescindível para o capital o estabelecimento de uma ordem produtiva que se apoie na divisão hierárquica do trabalho e tenha como base a alienação. Isto se deve ao fato de que para organizar a produção de modo a otimizar a extração da mais-valia necessária para a acumulação, o produtor deve ser um sujeito alienado do seu produto e, mais profundamente, essa configuração se dá já que "as funções de produção e de controle do processo de trabalho devem estar radicalmente separadas uma da outra e atribuídas a diferentes classes de indivíduos” (MÉSZÁROS, 2002, p. 99, grifos do autor). Não pode caber ao produtor as funções de controle, já que ao possuir tal domínio os trabalhadores estariam aptos a inverter as prioridades, isto é, a retirar o capital como centro da configuração do metabolismo social. De todo modo, ressalta Mészáros, o controle de fato sobre o capital foge inclusive daqueles que o filósofo denomina personificações do capital - que no capitalismo, são os capitalistas.

Conforme explica Mészaros,

os próprios atores humanos como "controladores" do sistema estão sendo de modo geral controlados e, portanto, em última análise, não se pode afirmar a existência de qualquer representante humano autodeterminante no controle do sistema. Esse modo peculiar de controle sem sujeito, em que o controlador é na verdade controlado pelas exigências fetichistas do próprio sistema do capital, é inevitável, devido à separação radical entre produção e controle no âmago deste sistema (MÉSZÁROS, 2002, p. 126, grifos do autor) 
É certo que um sistema incontrolável, que é ao mesmo tempo um sistema que opera dentro de uma lógica de expansão irrefreável, é um sistema perigoso. A característica do capital em ignorar limites para a sua expansão não significa que não existam limites objetivos para tal. De todo modo, a ativação dos limites absolutos do capital será examinada a seguir. O que é preciso ter claro no presente momento é que o capital necessita da expansão, não por mero efeito contingente, mas porque o freamento da expansão e acumulação, por qualquer motivo que seja, tem efeitos catastróficos. A imposição de limitações - seja por tentativa de controle humano, seja por limitações naturais e objetivas - abre as avenidas das crises do capital. Mészáros ressalta a atualidade como um período de crise estrutural do capital, no qual "seus constituintes destrutivos avançam com força extrema, ativando o espectro da incontrolabilidade total numa forma que faz prever a autodestruição, tanto para este sistema reprodutivo social excepcional, em si, como para a humanidade em geral" (MÉSZÁROS, 2002, p. 100). Portanto, o capital - e seu imperativo de expansão e acumulação - não pode ser controlado nem por indivíduos e nem por Estados, ao mesmo tempo limitações naturais ao seu movimento são barreiras impostas contra as quais o capital se choca violentamente. Os efeitos das tentativas do capital em superar estas barreiras são catastróficos para as próprias condições de permanência do regime, mas também para as condições de existência da humanidade.

\section{A falha metabólica}

Sobre a relação entre capital e trabalho, Marx usa a analogia do vampiro. Já para tratar da relação entre o ser humano e a natureza, Marx vai muito além da analogia, transpondo o conceito de metabolismo - oriundo das ciências naturais para a sua análise social. Ao compreender a sociedade humana como imbuída de um metabolismo social, Marx leva para sua análise a compreensão de troca metabólica, processo bioquímico no qual "um organismo (ou uma determinada célula) extrai materiais e energia de seu meio ambiente e os converte, por meio de diversas relações metabólicas, nos ingredientes de seu crescimento" (CLARK; FOSTER, 2011, p. 118). É nestes termos que Marx caracteriza o trabalho, afirmando que "é, antes de tudo, um processo entre o homem e a natureza, processo este em que o homem, por sua própria ação, medeia, regula e controla seu metabolismo com 
a natureza” (MARX, 2013 [1867], p. 273). Como já mencionado na introdução, esta concepção é trabalhada por Marx desde seus primeiros escritos e o autor concede, portanto, grande relevância para a natureza, já que o trabalho é precisamente, antes de qualquer coisa, uma relação metabólica entre o homem e a natureza. Levando em conta a dimensão ontológica do trabalho (LUKÁCKS, 2013), se torna clara a relação indivisível, mas complexa, entre homem e natureza.

$\mathrm{O}$ autor que se destaca por resgatar o conceito de metabolismo em Marx dentro de uma perspectiva ecológica é o sociólogo marxista John Bellamy Foster. Na sua obra mais conhecida, denominada Marx's Ecology, o autor constata que $\operatorname{Marx}$

empregou o conceito [de metabolismo] tanto para se referir à interação metabólica real entre a natureza e a sociedade por meio do trabalho humano (o contexto usual em que o termo foi usado em suas obras), quanto em um sentido mais amplo (particularmente nos Grundrisse) para descrever o conjunto complexo, dinâmico e interdependente de necessidades e relações trazidas à luz e constantemente reproduzidas de forma alienada sob o capitalismo, e a questão da liberdade humana que isto levantou - todas as quais poderiam ser vistas como estando conectadas à forma como o metabolismo humano com a natureza se expressa através da organização concreta do trabalho humano. O conceito de metabolismo, portanto, assumiu tanto um significado ecológico específico quanto um significado social mais amplo (FOSTER, 2000, p. 158) 3

Foster resgata uma análise que Marx faz no Capital e que diz respeito à agricultura industrial e a relação com o solo. São passagens curtas, mas que para Foster revelam uma compreensão ecológica avant la lettre no pensamento do fundador do socialismo científico. Para compreender as colocações de Marx referente ao tema, é preciso lembrar que

\begin{abstract}
durante o século dezenove, o esgotamento da fertilidade do solo foi a principal preocupação ambiental da sociedade capitalista em toda a Europa e América do Norte (...) nas décadas de 1820 e 1830 na GrãBretanha, e logo depois nas outras economias capitalistas em desenvolvimento da Europa e América do Norte, as preocupações generalizadas sobre o "esgotamento do solo" levaram ao pânico e a um aumento fenomenal na demanda por fertilizantes (FOSTER, 2000, p. 149150)
\end{abstract}

Este era um momento no qual as ciências naturais ainda não possuíam uma compreensão tão profunda sobre a dinâmica de nutrientes e produção de vegetais, com o estudo da química do solo ainda em estágio inicial. Igualmente, as técnicas

\footnotetext{
${ }^{3}$ Todas as citações referentes a este livro foram traduzidas livremente do original em inglês. 
para aumento na fertilidade do solo eram muito rudimentares, constituindo em grande parte na busca de fontes naturais para fertilização - era muito comum no período a utilização massiva de ossos nas plantações, para a absorção de fosfato, e nesse período começa a extração de guano na América Latina, tendo em vista os mesmos fins. Apenas na década de 1840 será produzido o primeiro fertilizante industrial, o "superfosfato" de J. B. Lawes (FOSTER, 2000, p. 150), que será difundido gradualmente pelo mundo. Esta crise de fertilidade do solo é o que impulsiona o investimento em pesquisa na área, intentando compreender e solucionar a questão que está afetando a produtividade agrícola europeia e norteamericana no período. "A figura central nesta crise de fertilidade do solo foi o químico alemão Justus von Liebig” (FOSTER, 2002, p. 155)4, um químico que desempenhou um trabalho pioneiro em compreender o ciclo de nutrientes do solo, assim como os processos que levam ao esgotamento dos mesmos - processo que em obras mais maduras ele denomina de "roubo completo (...) seguido pelo completo esgotamento do solo. (...) É espoliação" (LIEBIG, 1859, p. 145,148)5. Marx não apenas conheceu os trabalhos de Liebig, mas os estudou metodicamente e fundamentou sua compreensão sobre a agricultura industrial a partir da obra do químico alemão. "Marx, estudando o trabalho dos químicos do solo, reconheceu que a crítica de Liebig sobre a agricultura moderna complementou e paralelizou sua própria crítica da economia política" (CLARK; YORK, 2005, p. 398) ${ }^{6}$. Liebig também se utilizou amplamente do conceito de metabolismo, o desenvolvendo ao longo da sua obra, que desempenhou um papel fundamental nos seus estudos sobre o solo. Foster detecta que a própria forma que Marx utiliza o termo metabolismo captou nuances dos debates científicos ao longo do tempo e jamais se apartou das concepções químicas e biológicos do uso do conceito (FOSTER, 2000, p. 160).

Tomando os acúmulos científicos elaborados por Liebig e a nascente química do solo, assim como a madura concepção de metabolismo, Marx avançou na sua caracterização da agricultura moderna e elabora a concepção de uma "falha" na "relação metabólica entre os seres humanos e a terra para capturar o estranhamento material dos seres humanos na sociedade capitalista das condições naturais que formaram a base de sua existência" (FOSTER, 2000, p. 163). Em confluência com a

\footnotetext{
${ }^{4}$ Todas as citações referentes a este livro foram traduzidas livremente do original em inglês.

${ }^{5}$ Todas as citações referentes a este livro foram traduzidas livremente do original em inglês.

${ }^{6}$ Todas as citações referentes a este artigo foram traduzidas livremente do original em inglês.
} 
noção de roubo e espoliação exposta por Liebig, Marx afirma que o progresso adquirido na agricultura industrial, ou seja, a sua otimização produtiva, acaba por ser contraditório, e "é um progresso na arte de saquear não só o trabalhador, mas também o solo, pois cada progresso alcançado no aumento da fertilidade do solo por certo período é ao mesmo tempo um progresso no esgotamento das fontes duradouras dessa fertilidade" (MARX, 2013 [1867], p. 465). Marx identifica assim uma falha metabólica na relação entre a sociedade capitalista e a natureza, já que

com a predominância sempre crescente da população urbana, amontoada em grandes centros pela produção capitalista, esta, por um lado, acumula a força motriz histórica da sociedade e, por outro lado, desvirtua o metabolismo entre o homem e a terra, isto é, o retorno ao solo daqueles elementos que the são constitutivos e foram consumidos pelo homem sob forma de alimentos e vestimentas, retorno que é a eterna condição natural da fertilidade permanente do solo (MARX, 2013 [1867], p. 464-465).

Foster destaca que

Marx observou que o ciclo de nutrientes do solo necessitava da constante reciclagem de nitrogênio, fósforo e potássio, uma vez que as plantas os absorvem conforme crescem. Os resíduos gerados por plantas e humanos nas primeiras sociedades agrícolas não capitalistas costumavam retornar ao solo na forma de fertilizante, ajudando a repor os nutrientes perdidos. Porém, o movimento de cercamento e a privatização da terra que acompanharam o advento do capitalismo criaram uma divisão entre cidade e campo, desalojando grade parte da população rural e expandindo a urbana (CLARK; FOSTER, 2011, p. 119).

Marx, apoiado nos trabalhos de Liebig, identifica uma crise ecológica ressaltando, novamente, avant la lettre - causada diretamente pela lógica do próprio capital. Os imperativos deste regime sociometabólico demandam a concentração urbana em decorrência da necessidade de uma maior produção, assim como a alocação do seu exército de reserva. De tal modo, a ruptura exercida na sociedade, originando a separação radical entre campo e cidade, opera consequências profundas na cadeia de produção de alimentos. Como é possível afirmar a partir das reflexões de Marx, o aumento da exploração do trabalhador urbano e do trabalhador rural se refletem em mesmo nível na exploração da própria natureza, aqui representada pela espoliação - como aponta Liebig - e saque como afirma Marx - do solo. Por óbvio, as consequências não se limitam ao ciclo natural de restauração de nutrientes da terra, mas afeta toda a cadeia de relações entre humanos, enquanto sociedade, e entre humanos e natureza. Por exemplo, “ a degradação do solo levou a uma maior concentração de terras agrícolas entre um 
pequeno número de proprietários que adotaram métodos ainda mais intensivos de produção, incluindo a aplicação de fertilizantes artificiais” (CLARK; YORK, 2005, p. 398). Isto é, a degradação do solo está conectada com a expropriação das terras de camponeses, adquiridas ou roubadas por grandes proprietários, que por sua vez intensificam o uso de métodos artificiais para "recuperar" a produtividade do solo - que como Marx aponta, resulta em um ciclo ainda maior de degradação a longo prazo. Assim, a crise do solo é uma crise da sociedade como um todo, já que seus impactos sociais imediatos - como a falta de alimentos, por exemplo - se articulam a impactos sociais mais amplos, mais estruturais e de maior prazo. É claro, um dos efeitos de Marx conceitualizar e analisar essa situação antes de existir uma teoria ecológica de fato, é de que existem lacunas na sua análise e, por mais que haja uma articulação clara entre a preservação e boa relação com os ciclos da natureza, não há ainda uma teoria mais profunda sobre a relação entre o regime sociometabólico do capital e a degradação do mundo natural. De todo modo, fica claro que para Marx a destruição da natureza está intimamente ligada com o desenvolvimento do capital e que suas demandas são inconciliáveis com as necessidades da natureza. Portanto, se no tempo de Marx já era identificável a falha metabólica gerada pelo avanço do capital, é possível afirmar que na atualidade essa falha se generaliza, aprofunda e toma contornos cada vez mais críticos.

\section{Os limites absolutos do capital e a crise ecológica}

John Bellamy Foster, Brett Clark e Richard York - três dos maiores representantes do "marxismo ecológico", ou "ecossocialismo" - visam trazer a ideia de "falha metabólica" para os dias atuais na obra The Ecological Rift (2010). Apoiados por pesquisas coordenadas por cientistas e agências internacionais, os autores tratam de nove limites planetários, sendo eles: "acidificação do oceano, destruição estratosférica da camada de ozônio, os ciclos de nitrogênio e fósforo, uso global da água doce potável, mudança no uso da terra, perda de biodiversidade, carregamento atmosférico de aerossol e poluição química” (CLARK; FOSTER; YORK, 2010, p. 14) 7, além do aquecimento global. Em um ponto no qual as catástrofes, que emergem como consequência destes limites serem ignorados, se

\footnotetext{
${ }^{7}$ Todas as citações referentes a este livro foram traduzidas livremente do original em inglês. 
multiplicam, os representantes do capital - tanto os que ocupam as cadeiras dos conselhos empresariais, quanto os que ocupam as cadeiras dos parlamentos visam mitigar os efeitos que se apresentam. De todo modo, a realidade é que todas as ações que vão nessa direção operam estritamente dentro dos limites estipulados pelo regime do capital. Um exemplo da forma pela qual

\begin{abstract}
o capital se desloca em torno dos problemas ecológicos é por meio do simples deslocamento geográfico - uma vez que os recursos se esgotam em uma região, os capitalistas procuram em toda parte para tomar o controle de recursos em outras partes do mundo, seja pela força militar ou pelos mercados (CLARK; FOSTER; YORK, 2010, p. 74).
\end{abstract}

Isto é, se trata da função de deslocamento das contradições através da expansão. Um caso, para dar maior concretude à análise, é o da Noruega. País exaltado por sua atuação na conservação da natureza - estritamente dentro do seu território nacional, é claro, como no caso no qual o governo se recusou a perfurar um poço de petróleo que renderia milhões em receita (COCKBURN, 2019) -, mas que em países da América Latina está ligado à mineração com altos resultados destrutivos (SENRA, 2018).

O trio de sociólogos eco-marxistas destaca que

o desenvolvimento do capitalismo, seja através do colonialismo, imperialismo, ou forças de mercado, expandiram a falha metabólica para o nível global, à medida que regiões distantes através dos oceanos foram colocadas em produção para servir aos interesses dos capitalistas nas nações centrais (CLARK; FOSTER; YORK, 2010, p. 75).

Com a totalidade extensiva tendo seus limites esgotados, o capital radicaliza sua totalidade intensiva. Assim a sociedade se defronta com outra contradição básica do sistema do capital, isto é, "que ele não pode separar 'avanço' de destruição, nem "progresso" de desperdício - ainda que as resultantes sejam catastróficas" (MÉSZÁROS, 2011, p. 73, grifos do autor). "O fato do capitalismo lidar dessa forma - ou seja, a seu modo - com a ecologia não deveria provocar a mínima surpresa: seria quase um milagre se não fosse assim" (MÉSZÁROS, 2011, p. 52), já que, como demonstrado por Mészáros, o capital é movido por um imperativo de expansão e "para esse imperativo, não pode haver isenção. Nem mesmo quando as consequências devastadoras já são flagrantemente evidentes tanto no campo da produção quanto no campo da ecologia" (MÉSZÁROS, 2008, p. 22) ${ }^{8}$. Por razões

\footnotetext{
${ }^{8}$ Todas as citações referentes a este livro foram traduzidas da versão venezuelana. 
como estas, a questão ecológica é uma das questões não integráveis (MÉSZÁROS, 2002, p. 95) do capital. Isto é, os problemas concernentes à destruição ecológica não podem ser solucionados dentro do regime do capital, já que a causa dos problemas ambientais está ligada a imperativos fundamentais do capital. É nestes termos que a questão ecológica se apresenta como um limite absoluto do capital. Mészáros faz a distinção entre os limites relativos e os limites absolutos do capital:

\begin{abstract}
Os limites relativos do sistema são os que podem ser superados quando se expande progressivamente a margem e a eficiência produtiva - dentro da estrutura viável e do tipo buscado - da ação socioeconômica, minimizando por algum tempo os efeitos danosos que surgem e podem ser contidos pela estrutura causal fundamental do capital. Em contraste, a abordagem dos limites absolutos do capital inevitavelmente coloca em ação a própria estrutura causal. Consequentemente, ultrapassá-los exigiria a adoção de estratégias reprodutivas que, mais cedo ou mais tarde, enfraqueceriam inteiramente a viabilidade do sistema do capital em si (MÉSZÁROS, 2002, p. 175).
\end{abstract}

Como o regime do capital não permite restrições, sendo incontrolável, e a questão ecológica inevitavelmente imporia limitações ao capital - especialmente ao seu vital imperativo de expansão - , o capital necessariamente precisa buscar ultrapassar os limites naturais do planeta.

\begin{abstract}
Foi apenas uma questão de tempo para que o capital - em seu irrefreável impulso para ir além dos limites encontrados - tivesse de se superar, contradizendo sua lógica interna e entrando em colisão com os limites estruturais insuperáveis de seu próprio modo de controle sociometabólico. (...) É impossível pensar em qualquer coisa associada às condições elementares da reprodução sociometabólica que não esteja letalmente ameaçada pela forma como o capital se relaciona com elas: a única que ele conhece. Isto não vale apenas para as exigências de energia da humanidade ou para a administração dos recursos naturais e dos potenciais químicos do planeta, mas para todas as facetas da agricultura global, inclusive a devastação em grande escala das florestas e a maneira irresponsável de tratar o elemento sem o qual nenhum ser vivo pode sobreviver: a água. (MÉSZÁROS, 2002, p. 253).
\end{abstract}

Ao sistema do capital é impensável conceber qualquer tipo de ação responsável para a "reprodução da natureza, que pode incluir escalas de tempo de cem anos ou mais, para não mencionar a manutenção dos particularmente integrados ciclos naturais que ajudam a manter as condições de vida" (CLARK; FOSTER; YORK, 2010, p. 85). Estas são razões que devem preocupar a humanidade como um todo, pois a extinção das condições de reprodução do regime sociometabólico do capital não significa apenas o fim deste sistema, mas a própria extinção da humanidade. Se superar a crise ecológica significa superar o capital, a 
necessidade de permanência da espécie humana parece ser, logicamente, a missão de encontrar outro elemento que possa ser o centro do metabolismo social da sociedade. A forma de fazê-lo, ou como deveria se configurar, ainda está em debate, mas um comentário de Marx talvez deixe indicativos de como deve soar essa nova configuração social:

Do ponto de vista de uma formação econômica superior da sociedade, a propriedade privada do globo terrestre nas mãos de indivíduos isolados parecerá tão absurda quanto a propriedade privada de um ser humano sobre outro ser humano. Mesmo uma sociedade inteira, uma nação, ou, ainda mais, todas as sociedades contemporâneas reunidas não são proprietárias da Terra. São apenas possuidoras, usufrutuárias dela, e, como boni patres familias, devem legá-la melhorada às gerações seguintes (MARX, 2017b, p. 836, grifos do autor).

\section{Conclusão}

É possível identificar a relação entre as crises ecológicas - ou falhas metabólicas - com o mecanismo próprio de funcionamento do regime sociometabólico do capital. Isto é, os elementos fundamentais da estrutura do capital, seus imperativos e necessidades, entram em conflito direito com as necessidades metabólicas da Terra. $\mathrm{O}$ esgotamento das possibilidades de expansão territorial - mecanismo vital para a acumulação de capital, mas também de deslocamento de contradições - impele o sistema a aprofundar a modalidade intensiva da sua totalidade. De tal modo, humanidade e natureza sofrem as consequências de um modelo cada vez mais orientado para extração bárbara de riqueza - seja a mais-valia dos trabalhadores, seja as riquezas do solo. A compreensão dessa dinâmica vem desde Marx, apesar da negação de muitos críticos. Como um autor sensível aos avanços científicos de todas as áreas, Marx de modo muito competente integrou os desenvolvimentos das ciências do solo à sua produção teórica, mas não limitando suas reflexões à produtividade da propriedade agrícola e sim compondo uma visão mais geral das dinâmicas dissonantes entre o aumento da produção e expansão do capital - cada vez mais aceleradas -, e os ciclos de regeneração da natureza, que são longos.

De todo modo, uma teoria socialista da ecologia depende de teorizações mais profundas do que as deixadas por Marx. As falhas metabólicas oriundas do regime do capital apenas se agravaram e se multiplicaram no decorrer dos séculos. Tanto os autores marxistas identificados com o ecossocialismo - como Foster, Clark e York -, quanto autores como Mészáros, que não se inclui nessa tradição, observam 
a crescente necessidade de teorizar uma transição ao socialismo que leve em conta as condições naturais do planeta. Pensar com Marx a transformação da sociedade é refletir uma transição sustentável para o conjunto da humanidade.

\section{Referências}

CLARK, Brett; FOSTER, John Bellamy. A Dialética do Metabolismo Social e Ecológico. In: JINKINGS, Ivana; NOBILE, Rodrigo. István Mészáros e os Desafios do Tempo Histórico. São Paulo: Boitempo, 2011.

CLARK, Brett; FOSTER, John Bellamy; YORK, Richard. The Ecological Rift. Nova York: Monthly Review Press, 2010.

CLARK, Brett; YORK, Richard. Carbon metabolism: Global capitalism, climate change, and the biospheric Rift. Theory and Society, vol. 34, p. 391-428, 2005.

COCKBURN, Henry. Norway refuses to drill for billions of barrels of oil in Arctic, leaving 'whole industry surprised and disappointed'. Independent, Londres, 2019. Disponível em: https://www.independent.co.uk/environment/norway-oil-drillingarctic-ban-labor-party-unions-a8861171.htmlreader2/page. Acesso em: 26 de novembro de 2020.

COGGIOLA, Osvaldo. A Colonização da América e a Acumulação Originária do Capital. Jus Humanum - Revista Eletrônica de Ciências Jurídicas e Sociais da Universidade de Cruzeiro do Sul, São Paulo, vol. 1, n, 1, p. 140-174, 2011.

DUSSEL, Enrique. 1492, El Encubrimiento del Outro. La Paz: Plural, 1994.

FOSTER, John Bellamy. Ecology Against Capitalism. Nova York: Monthly Review Press, 2002.

FOSTER, John Bellamy. Marx’s Ecology. Nova York: Monthly Review Press, 2000.

FOSTER, John Bellamy. Vulnerable Planet. Nova York: Monthly Review Press, 1999.

LIEBIG, Justus Von. Letters on Modern Agriculture. Nova York: John Wiley and Sons, 1859.

LUKÁCS, Georg. Para uma Ontologia do Ser Social. São Paulo: Boitempo, 2013.

MARX, Karl. Crítica do Programa de Gotha. São Paulo: Boitempo, 2012.

MARX, Karl. Manuscritos Econômico-Filosóficos. São Paulo: Boitempo, 2010.

MARX, Karl. O Capital [Livro I]. São Paulo: Boitempo, 2013.

MARX, Karl. O Capital [livro III]. São Paulo: Boitempo, $2017 \mathrm{~b}$. 
MARX, Karl. O Manifesto do Partido Comunista. São Paulo: Expressão Popular, 2008.

MARX, Karl. Os Despossuídos. São Paulo: Boitempo, 2017a.

MÉSZÁROS, István. A Crise Estrutural do Capital. São Páulo, Boitempo, 2011.

MÉSZÁROS, István. A Montanha que Devemos Conquistar. São Paulo: Boitempo, 2013.

MÉSZÁROS, István. El Desafío y la Carga del Tiempo Histórico. Caracas: El perro y la rana, 2008.

MÉSZÁROS, István. O Poder da Ideologia. São Paulo: Boitempo, 2004.

MÉSZÁROS, István. Para Além do Capital. São Paulo: Boitempo, 2002.

MELO, Edvânia. Mészáros e a Crítica ao Reformismo da Social-Democracia. São Paulo: Instituto Lukács, 2018.

PANIAGO, Maria Cristina. Mészáros e a Incontrolabilidade do Capital. São Paulo: Instituto Lukács, 2012.

QUERIDO, Fábio Mascaro. Atualização das esperanças pretéritas. Lutas Sociais, São Paulo, vol. 17, n. 30, p. 82-94, 2013.

SENRA, Ricardo. Mineradora norueguesa tinha 'duto clandestino' para lançar rejeitos em nascentes amazônicas. BBC News, São Paulo, 2018. Disponível em: https://www.bbc.com/portuguese/brasil-43162472 Acesso em: 26 de novembro de 2020.

Recebido em: 01/12/2020. Aprovado em: 11/12/2020. Publicado em: 26/12/2020. 